\title{
ANIMALS ETHICS IN NEW ZEALAND ART - A SOCIAL SCIENCE PERSPECTIVE
}

\author{
Jenny Aimers and Peter Walker
}

\section{INTRODUCTION}

This article examines art works from the Dunedin Public Art Gallery (DPAG) in order to understand the position of animal ethics within New Zealand (NZ) society. The research responds to the assertion that we take the animalhuman connection so much for granted, it is worthy of increased scrutiny.' Our decision to select a public art gallery as a source of data comes from the assumption that exposure to art and other types of visual references reinforces the social values inherent in our relationships with animals, ${ }^{2}$ and that art itself is representative of human and cultural identity. If we also accept the argument that art institutions can confer a civilising effect on society to encourage "morally just and proper behaviour", ${ }^{3}$ then we can also assume that the collection of a major public gallery provides a window on how New Zealand society views "proper" behaviour, in this case with regard to animal ethics.

\section{ANIMAL ETHICS}

Within the context of this paper, the companion discourses of humanism and post-humanism are central to our approach. While both of these discourses are broad and wide reaching, in the case of humanism, we have focused on the argument that human consciousness elevates the status of humans above other creatures. ${ }^{4}$ Influenced by the Christian Bible, anthropocentric discourse, evolutionary theory, and cartesian thought, ${ }^{5}$ humanists believe that humans have absolute dominion over the natural world and consider animals as irrational; to be placed in the position of the "Other", compared with rational humans who possess language and are capable of exceptional thought. ${ }^{6}$ As a result, the animal has fewer rights and protection under human laws, occupying an inferior position to humans. Any rights bestowed on animals such as their right to the five freedoms, ${ }^{7}$ are conditional on the animal also meeting human needs, such as occurs within free-range farming or responsible pet ownership. ${ }^{8}$ The underpinning of humanist ethics rests, therefore, upon humankind having the ultimate right to control and care for animals as they see fit; the natural laws of the animal are of little consideration, which is sometimes pejoratively referred to as being "speciest".

The discourse around post-humanist ethics extends beyond the natural world, however, for our purposes we focus our attention on the aspect of post-humanism that seeks to reject anthropocentric dominance, to situate humans as one of many natural species. ${ }^{9}$ Under post-humanist ethics, humans are positioned as having no inherent rights to control, dominate, or destroy nature. Human rights are comparable to animal rights within a power neutral spectrum. Human limitations are acknowledged, not to undermine rational thought inherent in humanism, but to provide space for other (non-human animal) intelligences to exist. Assumptions of human dogma across such fields as science, philosophy, and politics, are rejected in an attempt to re-establish what it is to be human. This requires a deconstruction of human thought discourses, to expose anthropocentric normative notions of our relationship with non-human animals and the environment. Post-human ethics also acknowledges that humans normalise violence towards animals, and such violence undermines the humanity of the perpetrator. Furthermore, animals obey different laws than humans and do not bow to the supposed superiority of human laws. ${ }^{10}$ 


\section{METHODOLOGY AND METHOD}

As social science researchers we aim to maintain rigour and scientific transparency " by outlining here, our approach to articulating our data. Our data set consisted of six art works by New Zealand artists, selected in order to expose animal ethics discourses within the context of animal representation. In order to determine our sample, we restricted our scope to ensure that the research setting had a sense of boundedness (culture, time, and place) enabling it to provide a variety of relevant, interconnected, accessible data. To that end, we reviewed New Zealand figurative and landscape artwork, available as open access digital copies online, from a single public collection at Dunedin Public Art Gallery. From this, we selected a sample of six works that could illustrate discourses in relation to humanism and post-humanism in animal representation in New Zealand art. In preparation for analysis, we described the works and then identified the social or cultural contexts (culture, time and place) relevant to viewing the animal subjects. We chose Dunedin Public Art Gallery as a significant collection of art, and the oldest public art gallery in New Zealand, on the assumption that it is representative of New Zealand artwork since Pākehā settlement. Please note that as we are Pākehā, we are not qualified to research the cultural nuance in Te Ao Maori and have restricted ourselves to examining work from Pākehā artists.

In our analysis, we applied two principles drawn from the intersection of humanist and post-humanist ethics, namely:

a. The application or threat of violence on non-human animals as an ethically accepted right of humans, based on moral superiority and rationalism under humanism. This includes: slaughter for food or clothing, and euthanasia and physical punishment as part of control of animal behaviour (noting that these actions can be seen to diminish our humanity).

b. The laws and sets of behaviour recognised by post-humanism, whereby different species of non-human animals abide by their own laws when unimpeded by humans.

We considered how the representation of animals in each art work reflect and/or expose either of these ethical principles.

\section{THE ARTWORKS}

The six art works we selected represented a century of Pākehā artist endeavor, from the 1880s to the 1980s. Mediums included photography, serigraph, oil painting, and watercolour, thereby offering an intermedia approach. The animal representations were variously described as domestic, abject or celebratory, however we were mindful that whatever taxonomy we ascribe to these animals did not change the essential nature of the animal itself, but only how our society values or uses them. ${ }^{12}$ The works are presented here in chronological order.

In Richmond's ${ }^{3}$ I 887 work, Mount Excelsior, Takitimu Range, we can see tiny cattle, horses, and flying birds used as points of perspective, from which Richmond contrasts the pastoral landscape of the Takitimu Range. The horses in the foreground are considerably larger than the cattle in the middle distance, and both serve to give scale to the mountains, which dominate the work at the horizon. The soft pale rendering of the watercolour medium highlights domesticated animals as graceful elements of an idyllic pastoral scene. During the late 1800s, colonialism was well established and fast becoming the dominant force in New Zealand, and paintings of an idyllic landscape were often utilised to promote British settlement. ${ }^{14}$ While the animals are unhampered by fences or restrictions, seemingly free to live according to their natural laws, the time and context suggests otherwise as horses were integral forms of labour for the colonists and the cattle were a source of food. Our natural humanist bias tends to see the pastoral landscape as culturally invisible; ${ }^{15}$ we are so accustomed to seeing domesticated farm animals in such a landscape that we consider what it represents as normal. However, animals farmed for their meat and other products are subject to the violence of humans, as a normal part of farming: early weaning the calf from its mother, dehorning, 


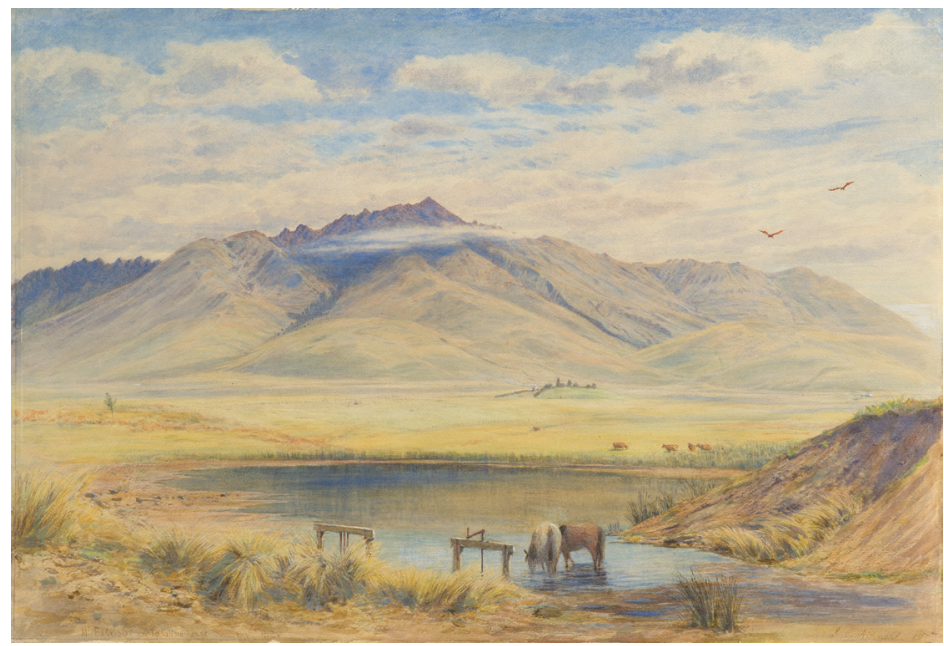

Figure I. James Crowe Richmond, Mount Excelsior, Takitimu Range. Southland N.Z, 1887, watercolour, $516 \times 751 \mathrm{~mm}$. Reproduced with permission, collection of the

Dunedin Public Art Gallery.

and tail docking are all preparing the animal for eventual slaughter. The horses are subject to early weaning, restraint, and training as discipline is applied, including the use of bits, whips, and spurs. Whilst horse meat is not commonly used for human consumption in this country, horses are slaughtered and disposed of when their useful life is ended. Thanks to the work undertaken in Britain in the 1920s, legislative protection for animals was introduced, and as a colony of Britain, New Zealand followed suit. The first Society for the Prevention of Cruelty to Animals (SPCA) was established in 1884 to enforce animal welfare legislation (primarily to horses, cattle and sheep). ${ }^{16}$ Such protection offered animals, deemed as stock or working animals, a modicum of protection from cruel and neglectful behaviour. However, stock management disrupts the formation of familial social groups necessary for herd animals to maintain their own natural hierarchies of power, and we cannot forget that all farming ends in slaughter.

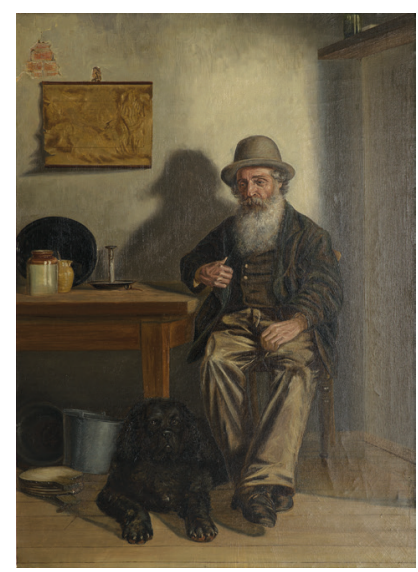

Figure 2. David Con Hutton, Old Man and Black Dog, date unknown, oil on canvas, $915 \times 660 \mathrm{~mm}$. Reproduced with permission collection of the

Dunedin Public Art Gallery.
David Hutton's ${ }^{17}$ oil painting is a study in anthropomorphism, here we have an elderly man enjoying the company of his dog, in what we presume is his home or public house (a humble abode where both are comfortable and safe). The use of dark greens and browns add to the soft, homeliness of the interior. The dog is focused on the viewer, while the man looks toward something out of view, to the left of the painting.

In the case of pet portraiture, the family dog is often used as a symbol of house and home, as well as to symbolise the notion of familial unconditional love. ${ }^{18}$ Viewing this work in the context of Victorian values, highlights the dual concepts of safe "home" and unsafe "homelessness". A home reflected middle-class values, and was idealised as somewhere that a pet was cared for, and that promoted the domestic ethic of practicing kindness to animals. Stray or homeless animals were also a resource for vivisection laboratories, or were seen as potential carriers of disease and with possibly dangerous behaviour, presenting a public health concern that added weight to the negative connotations of "stray". Thus, "home" was a space of control, and part of the civilising mission of the Western philosophy of colonisation and benevolence. This concern for the 
benevolent treatment of (primarily) cats and dogs, also went hand in hand with an awareness of child protection, as children and pets occupied a similar status. Owning and caring for a pet, ironically, made us more human.

We see the pet anthropomorphically, even allegorically as a reflection of ourselves. In the case of Hutton's man and his dog, this is illustrated by the way the man and dog are closely situated, companionable, and forming a comfortable social relationship. We like and trust the man more, for the presence of his dog. The attachment between humans and pets, and how they relate, is complex. Yet when examined closely, the term "pet ownership" is clearly in the humanist camp. There is social disruption inherent in domestication, forms of violence in physical and psychological discipline, the potential for pet abuse and neglect, and the final violent act of "humane" euthanasia. If left in a wild state, dogs become pack animals having little or no regard to human laws and mores.

Kate Ogston's 1888 oil painting, New Zealand Game, shows a dead kea as a still life, in rich earthy colours that highlight the bird's plumage within an indeterminate background. The kea is posed in the foreground, with a wing casually spread to display the forest hues of the plumage with a flash of orange under the wing. It is, however, the title that gives us the clue into the context of this work, "New Zealand Game" places the dead Kea as a pest. Although initially considered only a fruit and nectar feeder, the kea became increasing implicated in the killing of sheep during the 1800s, with farmers claiming a 30\%-40\% loss of stock from kea predation. ${ }^{19}$ By the 1900s, this claim was challenged as overly inflated, but in the minds of the public, the kea as a sheep killer was well established. This work is a profoundly interesting piece, while small in size, and appearing modest and domestic in nature, it captures a moment before native birds became protected and celebrated. To the contemporary eye this is shocking, as we are used to revering the native bird. To see this still-life/still-death is deeply ironic, in that the bird is killed to protect a farm animal that will also be killed; pest eradication merely allows the farmer to choose the time and

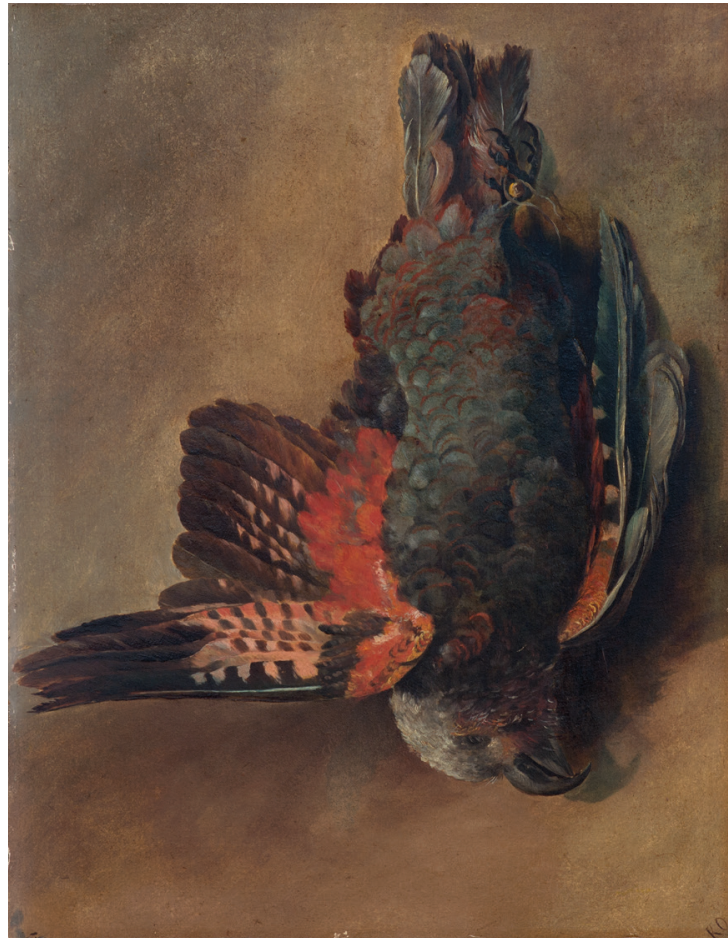

Figure 3. Kate Mary Ogston, New Zealand Game, I888,

oil on board, $460 \times 355 \mathrm{~mm}$. Reproduced with permission, collection of the Dunedin Public Art Gallery. place of death. The natural behaviour of a predator also directly challenges human property rights, depriving the farmer of income and control. This illustrates an important aspect of humanism, that is, it is up to the human to assign status of pest or protected.

Don Binney's ${ }^{20}$ serigraph Swoop of the Kotare, Wainamu, depicts a New Zealand native bird in full flight over a wild, remote location, devoid of buildings or obvious signs of human influence. The flattened image and use of block colour, reflect a modernist register.

Binney has been described as one of the few New Zealand artists to represent animals as animals, with their identity their own, not as a representation of human[ist] culture. ${ }^{21}$ Binney has explained the prominence of the bird in the landscape is from his ornithological practice of viewing birds through binoculars, which magnify the 
bird in relation to its surroundings. He also states that he sees the placement of the bird to be in the environment, rather than in a landscape, and that this in some regards is a direct critique the $18^{\text {th }}$ and $19^{\text {th }}$ century romanticised landscape. ${ }^{22}$ Binney, therefore, is presenting his birds in a post-humanist way; his work is concerned with the exploration of the birds' experience of their environment, be it natural or built. As an ornithologist, Binney may well have been influenced by the burgeoning environmental movement. From the 1970s-2000s the environmental movement launched numerous successful campaigns to protect native forest and the species who dwell within. ${ }^{23}$ While the protection of the indigenous environment could be argued as responding to post-humanist ethics, the subsequent management practices relied on the destruction of "pest" species such as rats and possums, where again humans decide which species is worthy of protection.

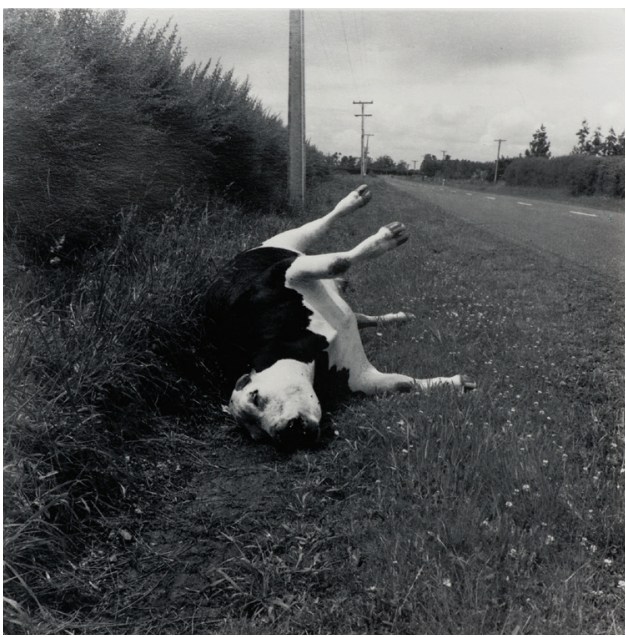

Figure 5. Peter Peryer, Dead Steer, 1987, silver gelatin print, $190 \times 187 \mathrm{~mm}$. By permission of the Estate of Peter Peryer, collection of the Dunedin Public Art Gallery.

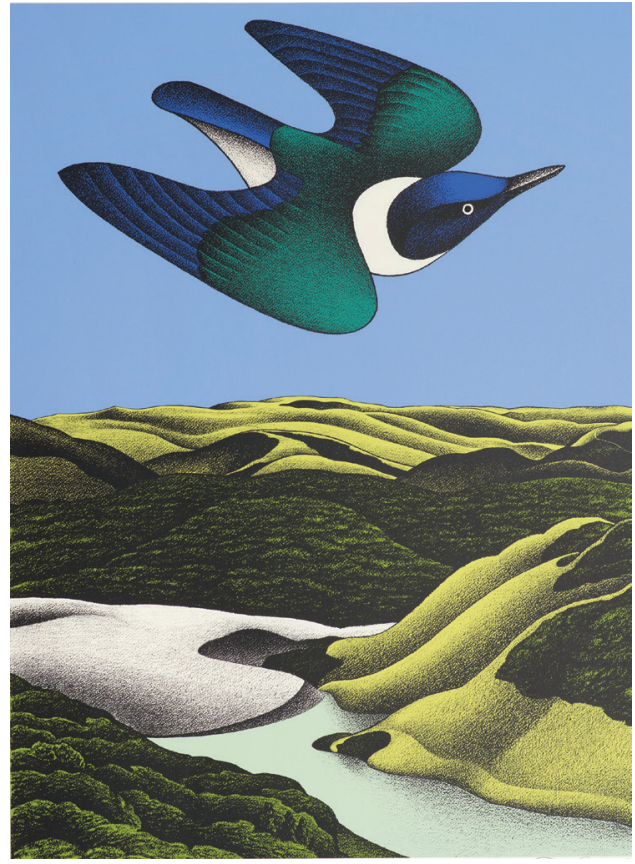

Figure 4. Don Binney, Swoop of the Kotare, Wainamu, 1980, serigraph, $625 \times 456 \mathrm{~mm}$. By permission of Philipa Binney, collection of the Dunedin Public Art Gallery.

As noted with Richmond's work, New Zealand's natural environment has been a driver behind both immigration and vacation advertising campaigns since colonial times. There is no suggestion of violence here, the human is absent. Brown ${ }^{24}$ asserts that, with a few notable exceptions, animals in New Zealand art are rarely portrayed as themselves, as sentient and prescient, but here, without doubt, the native bird is responding to its own laws on its own terms.

Peter Peryer's ${ }^{25}$ photograph, Dead Steer, is an abject image of a bloated cattle beast, dead on the side of the road. Peryer portrays the pastoral as death, brutal and visceral, in a stark black and white image of an animal destined for food, but for some reason discarded dead on the side of a rural road. Here the animal dominates the frame, challenging the viewer to consider the life and death that is an everyday reality in agricultural practice. The landscape of asphalt road, hedges and power poles underpins an industrially controlled, ubiquitous landscape, that is almost invisible. The dead steer is confronting, positioned unavoidably front and centre.

The advent of photography was an important tool allowing early animal rights activists to provide an authoritative representation of the everyday practices that led to animal suffering, and allowed the general public to see inside the slaughterhouse. ${ }^{26}$ By the 1970s, liberation movements paved the way for the animal liberation movement, which sought to create an awareness for the sentience of animals on a par with humans, and counter what is described as specieist beliefs, elevating the rights of humans over animals. ${ }^{27}$ At the same time, anti-vivisection movements 
flourished in New Zealand, leading to the creation the National Vivisection Action Committee (NVAC) and Save Animals from Exploitation (SAFE). ${ }^{28}$ There is no doubt that Preyer's image is a critic of the violence inherent in animal husbandry. In an essay by Peryer in 2008, he details his childhood experiences on a Taranaki dairy farm, witnessing practices such as dehorning. Peryer's Dead Steer is one of his most well-known and controversial works. When it was exhibited in 1996 in Frankfurt Germany, in the midst of the mad cow disease outbreak in Europe, the New Zealand government (unsuccessfully) attempted to have the work removed as they were worried that this image would suggest New Zealand beef was affected by the disease, and hurt exports of beef at a time when these were already declining. ${ }^{29}$

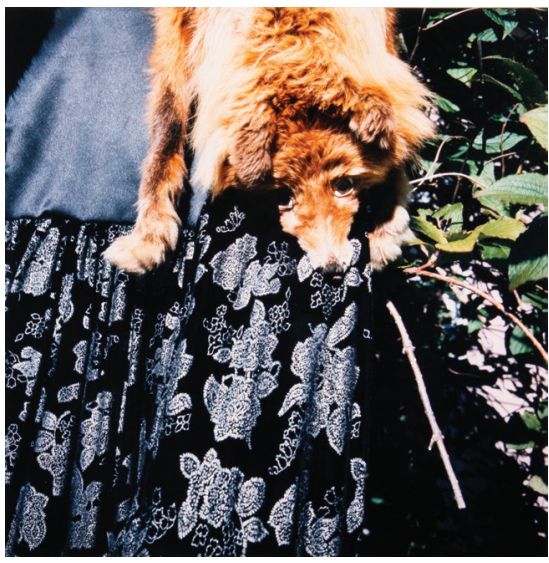

Figure 6. Mary Macpherson, Fabrication 4, 1988 , colour photograph, $275 \times 275 \mathrm{~mm}$. By permission of Mary Macpherson, collection of the Dunedin Public Art Gallery.
It is worth noting that while looking through the Dunedin Public Art Gallery collection of New Zealand art, we found animals in a pastoral setting were largely absent, it has been $\operatorname{argued}^{30}$ that post-war urbanisation has led the "nationalist eye" toward an "ecologically constructed", sublime, primordial environment, resulting in the farm animal being largely absent from New Zealand contemporary art. This serves to make Peryer's work all the more important to the post-humanist discourse, as he confronts us with the gritty reality for farmed animals under humanism.

Mary Macpherson's ${ }^{31} 1988$ photograph, fabrication 4, is colour photograph that highlights texture, movement and colour of differing fabrics that adorn humans. In this image, we focus on the dead fox, constructed as a stole, and likely produced in the 1940s, when they were popular for a brief period. By the 1970s, these fox furs were common in second-hand clothing stores or Op shops, and became sought after by young alternative dressers in the 1970s-80s. ${ }^{32}$ Dunedin indie band, The Verlaines, captured this in their 1987 song Joed Out: ".... your hair is as soft as the fox fur you wear..."33

While the fox is not found in New Zealand, this image represents our predilection for using animal skin or pelts as clothing, for this could easily be possum fur or lamb skin. This is another example of the violence that is acceptable under a humanist ethical position. The fox in Europe is a pest, but perhaps more importantly when this garment was likely produced, fur was a symbol of luxury and slaughter and skinning was not considered unethical within this context. By the 1980s, fur was falling out of favour, as animal liberation groups protested its use. Mooney's furrier actually bought up many vintage fox furs and re-made them into new garments, without the head during this period. ${ }^{34}$ This image reveals a change in perspective, firstly the humanist right to inflict violence to create a product, but also a hint in the abject gaze of the dead fox, that society is becoming more influenced by posthumanist thinking, such that such practices appear increasingly abhorrent and diminishing for the hunter/farmer, furrier and the customer.

\section{CONCLUSION}

As we reflect on the ethical position these works represent, we must keep in mind our earlier statement that our analysis does not change the essential nature of the animal itself but only how our society values or uses them.

The works that display New Zealand's agricultural past are strongly located in a humanist vision in Richmond's romanticised pastoral scene. Hutton's work is also humanist as it is strongly anthropomorphic, represented by 
the companion animal the man and his dog. The humanist view is then strongly critiqued by depiction of animals as products. Overall, this reflects our insatiable hunger to control and tame the environment, as depicted by Richmond, alongside the flesh, pelt and dominion, as seen in the work of Ogston, Peryer and Macpherson. Peryer and Macpherson, in particular, illustrate that in this power play, it is the animal who suffers; the animal always dies.

Considering the two works depicting native birds, Ogston's work (where a Kea is slain for pest control thereby denying the bird's inherent sentience) is in stark contrast to Binney's interpretation of the emancipated native bird. Both are native species, but each is treated differently, based on their value to human constructs of the times: the humanist society of the 1800 s versus the beginnings of post-humanist thought highlighted within the animal liberation movement of the 1970s onwards.

In conclusion, these works appear, on the surface at least, to represent a maturing of societal mores, and an increasing rejection of humanist perspectives. However, if we dig deeper, increased concern for animal welfare in farmed animals, serves an economic purpose in the marketing of ethical produce. Indeed, protection of native species is not without the loss of other animal lives, and also provides an engaging image for our tourism campaigns. And the place of the companion animal, despite the inherent social contract, is without doubt on our terms and played out within the boundary of human rules.

Jenny Aimers (@ORCID No: https://orcid.org/0000-0002-7285-1053) is a research co-ordinator at Otago Polytechnic, she is a social science researcher with a background in community development and third sector organisational practice and research. She has a life-long interest in art and the human animal connection.

Dr Peter EWalker (DORCID No: https://orcid.org/0000-0002-I49|-2I53) is a senior lecturer in social work in the Department of Sociology, Gender and Criminology at the University of Otago. He has previously published on animal ethics in the helping professions and established the postgraduate paper titled "Animals in Social Work" in 2017.

I Annie Potts, Philip Armstrong and Deidre Brown, A New Zealand Book of Beasts: Animals in Our Culture, History and Everyday Life (Auckland, New Zealand: Auckland University Press, 2013).

2 J Keri Cronin, "Art for Animals: Visual Culture and Animal Advocacy, 1870-1914", in. Animalibus: Of Animals and Cultures (. University Park, Pennsylvania:The Pennsylvania State University Press, 2018).

3 Cronin, "Art for Animals", 39.

4 Peter Walker, Jenny Aimers and Clare Perry, "Animals and Social Work: An Emerging Field of Practice for Aotearoa New Zealand," Aotearoa New Zealand Social Work 27, no. I/2 (20I5): 24-35.

5 Peter Harrison, "Descartes on Animals," The Philosophical Quarterly 42, no. 167 (April 1992): 219, https://doi. org/10.2307/2220217.

6 Belinda Kleinhans, "Posthuman Ethics, Violence, Creaturely Suffering and the (Other) Animal: Schnurre's Postwar Animal Stories," Humanities 5, no. 3 (19 August 2016): 69, https://doi.org/ 10.3390/h5030069.

7 Peter Walker and Emma Tumilty, "Developing Ethical Frameworks in Animal-Assisted Social Service Delivery in Aotearoa New Zealand," The British Journal of Social Work 49, no. I (2019): I63-82, https://doi.org/l 0. I 093/bjsw/bcy020. 
8 Thomas Ryan, Animals and Social Work: A Moral Introduction (London: Palgrave Macmillan UK, 201 I), https://doi. org/10.1057/9780230306868.

9 Cary Wolfe, "What Is Posthumanism?" in Posthumanities Series, vol. 8 (Minneapolis: University of Minnesota Press, 20 I0).

10 "Sherbert - Revising Posthumanist Aesthetics in the Ethical Treatment of Nonhuman Animals," https://www.depauw.edu/ humanimalia/issue\%20 I6/sherbert.html (accessed 16 April 2020).

I I Adrian Holliday, Doing \& Writing Qualitative Research, 3rd edition (Los Angeles: SAGE, 20 I6).

12 Armstrong Potts and Brown, A New Zealand Book of Beasts.

13 James Crowe Richmond was born in London and trained as an engineer, arriving in New Zealand in |85| Richmond is described as a leading New Zealand watercolourist, he exhibited throughout New Zealand and as far as Australia. Una Platts, Nineteenth Century New Zealand Artists: A Guide and Handbook (Avon Fine Print, 1980).

14 Hamish Keith, The Big Picture: The History of New Zealand Art from 1642 (Auckland; Enfield: Random House New Zealand, Publishers Group UK, 2008).

15 Cronin, Art for Animals.

16 "About Us - SPCA New Zealand," https://www.spca.nz/about (accessed 20 March 2020).

17 David Con Hutton was born in Scotland and arrived in Dunedin, New Zealand in 1870 to take up the position of Drawing Master for the Provincial Government at what would become the Dunedin School of Art. His wash drawings and watercolours were known for their true primitive quality. He exhibited throughout New Zealand and Australia. Una Platts, Nineteenth Century New Zealand Artists: A Guide and Handbook (Avon Fine Print, 1980).

I8 D Brown, "Contemporary Art Animals," in A New Zealand Book of Beasts (Auckland University Press, 20 I3), I76- 197.

19 J Diamond and A Bond, Kea, Bird of Paradox (University of California Press, 1999).

20 Don Binney was born in Auckland, and over his career has exhibited widely throughout New Zealand and overseas, describing himself as a figurative painter concerned with the psychic metaphor of the environment. A keen birdwatcher, Binnie described this activity as a passage into the landscape and the opportunity to develop a personal relationship with it "Don Binney - ARTIS Gallery - Artists", 5 February 2013. https://web.archive.org/web/20130205 I 83926/http://artisgallery. co.nz/artists_show.asp?id=132.

21 Brown, "Contemporary Art Animals."

22 S Keith, "In Conversation with Don Binnie," Art New Zealand 28, no. Spring (1983).

23 Paul Bensemann, Fight for the Forests: The Pivotal Campaigns That Saved New Zealand's Native Forests (Nelson, New Zealand: Potton \& Burton, 20 I).

24 Brown, "Contemporary Art Animals."

25 Peter Peryer was originally a teacher, taking up photography in his 30s, he has widely exhibited throughout New Zealand and internationally, and was the recipient of several awards including an ONZM for his contribution to photography and Arts Laureate of New Zealand. Arts Foundation. Arts Foundation. "Peter Peryer, Arts Foundation Laureate," https://www.thearts. co.nz/artists/peter-peryer (accessed 20 March 2020)

26 Cronin, Art for Animals.

27 Peter Singer, Animal Liberation:A New Ethics for OurTreatment of Animals (New York: New York Review, Distributed by Random House, 1975).

28 Taonga, New Zealand Ministry for Culture and Heritage Te Manatu, "Animal Liberation and Animal Rights," https://teara.govt. nz/en/animal-welfare-and-rights/page-3 (accessed 16 April 2020).

29 Brown, "Contemporary Art Animals."

30 Ibid

31 Mary Macpherson is a Wellington photographer whose work is represented in many national collections including Te Papa, the Sarjeant Gallery, the Dowse Art Museum, the Dunedin Public Art Gallery. Her work emphasises projects that explore ideas about society and culture. "Mary Macpherson," http://www.photospacegallery.com/mary-macpherson.html (accessed 20 March 2020).

32 "New Zealand Fashion Museum," http://www.nzfashionmuseum.org.nz/mooneys-furs/ (accessed I6 April 2020).

33 The Verlaines, "Joed Out," in Juvenilia (Flying Nun Records, 1987).

34 "New Zealand Fashion Museum". 